$5-1-2008$

\title{
Intrasheath subluxation of the peroneal tendons.
}

\author{
Steven M Raikin \\ Department of Orthopaedic Surgery, Rothman Institute, Thomas Jefferson University Hospital
}

Ilan Elias

Department of Orthopaedic Surgery, Rothman Institute, Thomas Jefferson University Hospital

Levon N Nazarian

Division of Diagnostic Ultrasound, Department of Radiology, Thomas Jefferson University Hospital

Follow this and additional works at: https://jdc.jefferson.edu/radiologyfp

Part of the Radiology Commons

Let us know how access to this document benefits you

\section{Recommended Citation}

Raikin, Steven M; Elias, Ilan; and Nazarian, Levon N, "Intrasheath subluxation of the peroneal tendons." (2008). Department of Radiology Faculty Papers. Paper 25.

https://jdc.jefferson.edu/radiologyfp/25

This Article is brought to you for free and open access by the Jefferson Digital Commons. The Jefferson Digital Commons is a service of Thomas Jefferson University's Center for Teaching and Learning (CTL). The Commons is a showcase for Jefferson books and journals, peer-reviewed scholarly publications, unique historical collections from the University archives, and teaching tools. The Jefferson Digital Commons allows researchers and interested readers anywhere in the world to learn about and keep up to date with Jefferson scholarship. This article has been accepted for inclusion in Department of Radiology Faculty Papers by an authorized administrator of the Jefferson Digital Commons. For more information, please contact: JeffersonDigitalCommons@jefferson.edu. 


\title{
Intrasheath Subluxation of the Peroneal Tendons
}

\author{
By Steven M. Raikin, MD, Ilan Elias, MD, and Levon N. Nazarian, MD \\ Investigation performed at the Departments of Orthopaedic Surgery and Radiology, \\ Thomas Jefferson University Hospital, Philadelphia, Pennsylvania
}

\begin{abstract}
Background: Dislocation or subluxation of the peroneal tendons out of the peroneal groove under a torn or avulsed superior peroneal retinaculum has been well described. We identified a new subgroup of patients with intrasheath subluxation of these tendons within the peroneal groove and with an otherwise intact retinaculum.

Methods: The cases of fifty-seven patients with painful snapping of the peroneal tendons posterior to the fibula were reviewed. Of these, forty-three had tendons that could be reproducibly subluxated out of the groove with a dorsiflexioneversion maneuver of the ankle. Fourteen patients who could not subluxate the tendons out of the groove underwent a dynamic ultrasound examination of the tendons. While the same dorsiflexion and eversion maneuver was being performed, the tendons were seen to switch their relative positions (the peroneus longus came to lie deep to the peroneus brevis tendon) with a reproducible painful click. All fourteen patients underwent a peroneal groove-deepening procedure with retinacular reefing. Intraoperatively, thirteen patients were found to have a convex peroneal groove and all fourteen had an intact peroneal retinaculum. All patients subsequently underwent a follow-up dynamic ultrasound examination and an American Orthopaedic Foot and Ankle Society (AOFAS) ankle-hindfoot score evaluation at a minimum of twenty-four months after surgery.
\end{abstract}

Results: All fourteen patients were female, with an average age of thirty-five years. Two subtypes of intrasheath subluxation were found. Type A (ten patients) involved intact tendons with relative switching of their anatomic alignment. Type B (four patients) involved a longitudinal split within the peroneus brevis tendon through which the longus tendon subluxated. Intraoperative confirmation of the ultrasound findings was $100 \%$. At an average follow-up interval of thirty-three months, the average AOFAS score had improved from 61 points preoperatively to 93 points, and the average score on the 10-cm visual analog pain scale had improved from 6.8 to 1.2. Follow-up ultrasound evaluation revealed healed tendons without persistent subluxation in thirteen patients. Nine patients rated the result as excellent, four rated it as good, and one rated it as fair.

Conclusions: Patients with retrofibular pain and clicking of the peroneal tendons may not have demonstrable subluxation on physical examination and may have an intact superior peroneal retinaculum. They may have an intrasheath subluxation of the peroneal tendons, which can be confirmed with use of a dynamic ultrasound. Surgical repair of tendon tears combined with a peroneal groove-deepening procedure with retinacular reefing is a reproducibly effective procedure for this condition.

Level of Evidence: Therapeutic Level IV. See Instructions to Authors for a complete description of levels of evidence.

$\mathrm{D}$ islocation of the peroneal tendons from within the superior peroneal retinaculum around the posterolateral aspect of the fibula was first described by Monteggia in $1803^{1}$. Most acute dislocations are a result of an inversion and dorsiflexion injury of the foot and ankle, with simultaneous forceful contracture of the peroneal tendons $\mathrm{s}^{2-5}$. This leads to an avulsion of the superior peroneal retinaculum from its fibular insertion similar to a Bankart-type lesion in the shoulder. ${ }^{6}$. Unfortunately, the acute injuries are often missed or are misdiagnosed as an ankle sprain, and chronic or

Disclosure: In support of their research for or preparation of this work, one or more of the authors received, in any one year, outside funding or grants in excess of $\$ 10,000$ from Synthes. Neither they nor a member of their immediate families received payments or other benefits or a commitment or agreement to provide such benefits from a commercial entity. No commercial entity paid or directed, or agreed to pay or direct, any benefits to any research fund, foundation, division, center, clinical practice, or other charitable or nonprofit organization with which the authors, or a member of their immediate families, are affiliated or associated.

A video supplement to this article will be available from the Video Journal of Orthopaedics. A video clip will be available at the JBJS web site, www.jbjs.org. The Video Journal of Orthopaedics can be contacted at (805) 962-3410, web site: www.vjortho.com. 


\section{Normal Anatomy}

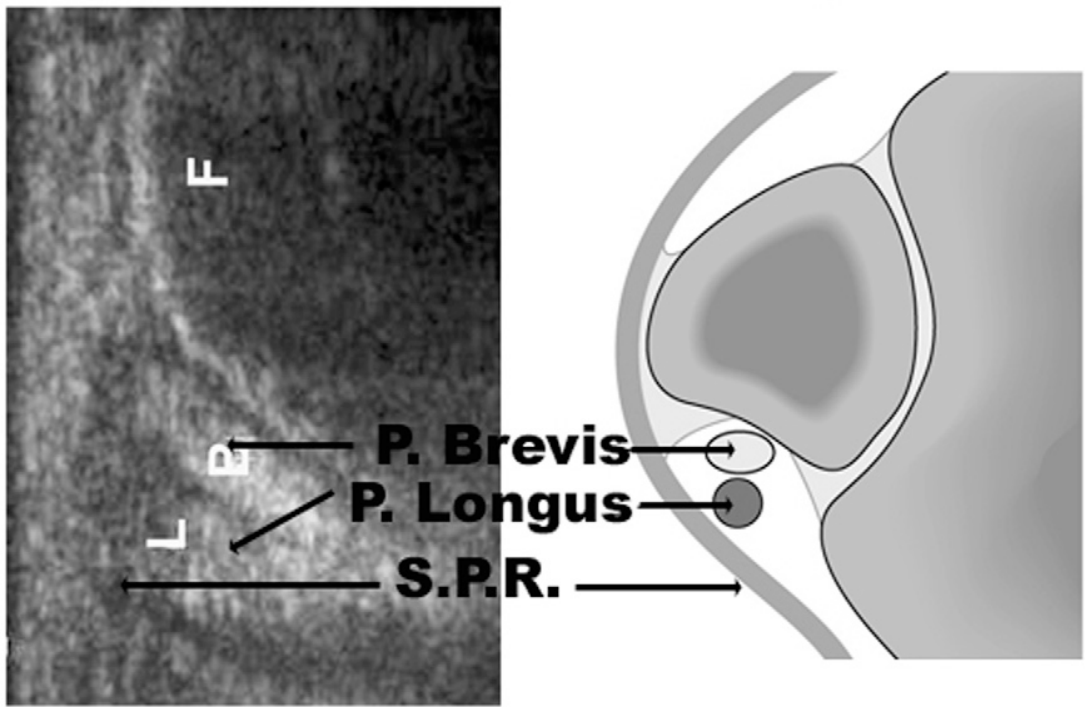

Fig. 1

The normal location of the peroneal tendons behind the fibula with an intact superior peroneal retinaculum (SPR) is depicted diagrammatically and on an ultrasound image. $\mathrm{L}=$ peroneus longus tendon, $\mathrm{F}=$ fibula, and $\mathrm{B}=$ peroneus brevis.

recurrent dislocation or subluxation of the peroneal tendons results.

The normal anatomy of the peroneal tendons at the level of the distal aspect of the fibula is depicted in Figure 1. Oden modified the classification of Eckert and Davis into four grades (Fig. 2) ${ }^{2}$. Grade-1 lesions occur when the superior peroneal retinaculum is elevated off the fibula with the peroneal tendons coming to lie between the bone and the periosteum. This is the most common pattern and is present in $>50 \%$ of patients with a lesion ${ }^{5-7}$. Grade-2 lesions occur when the fibrocartilaginous ridge behind the lateral insertion of the superior peroneal retinaculum avulses together with the retinaculum, and the tendons are displaced beneath the ridge. Grade- 3 lesions additionally involve an avulsion of a small cortical osseous fragment from the fibular insertion, with the tendons dislocating beneath the fibular fragment. Grade-4 lesions are the rarest type and involve a complete avulsion or rupture of the superior peroneal retinaculum with the tendons lying external and superficial to the retinaculum.

We became aware of a group of patients with symptoms consistent with peroneal tendon dislocation or subluxation who do not fit into the above classification. These patients are first seen with pain and tenderness of the peroneal tendons behind the fibula without clinically reproducible dislocation. On circumduction of the ankle (particularly at the phase of maximum eversion and dorsiflexion), a palpable and often painful clicking of the tendons can be felt, but the tendons remain within the peroneal groove. These patients may have symptoms recalcitrant to short-term brace immobilization and physical therapy. Dynamic ultrasound evaluation reveals that the peroneus brevis and longus tendons are subluxating over each other within the peroneal groove with an intact, uncompromised superior peroneal retinaculum. In the present study, we review the clinical presentation, radiographic evaluation, treatment, and outcomes of a series of patients with what we have termed intrasheath subluxation of the peroneal tendons. We propose a new classification for these lesions.

\section{Materials and Methods}

B etween 2000 and 2004, fifty-seven consecutive patients $\mathbf{B}_{\text {who were first seen at the clinic of the senior one of us }}$ (S.M.R.) with pain and motility dysfunction of the peroneal tendons that were recalcitrant to nonsurgical management were evaluated. Forty-three patients (75\%) were determined to fit within the previously described classification system of Eckert and Davis. Data on these patients are summarized in Table I. The fourteen remaining patients, all of whom were female, presented with pain and dysfunction of the peroneal tendons without reproducible dislocation or subluxation of the tendon(s) out of the peroneal groove. Eight of them were aware of clicking behind the ankle, which was painful and occurred with activity. The average age of the patients was thirty-four years (range, fifteen to fifty-three years). The right and left ankle were involved in seven patients each. Eleven of the fourteen patients had a history of a predisposing ankle sprain with an inversion-type mechanism of injury, and they were initially diagnosed and treated as having an ankle sprain. Three patients were not aware of a specific injury to the ankle as an initiating causative event, but all had described prior minor ankle-twisting injuries within six months of the symptom onset. Eleven of the fourteen patients had undergone 
Grade 1

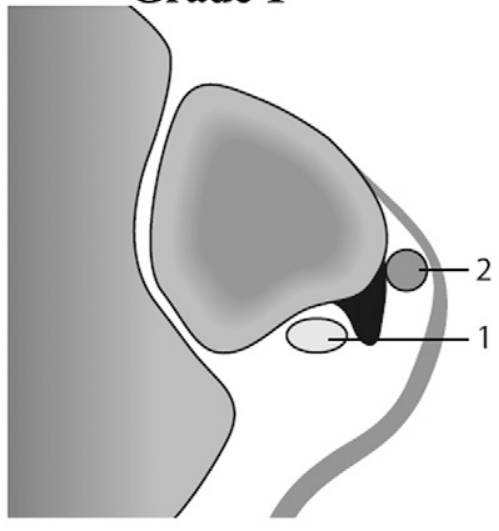

\section{Grade 3}

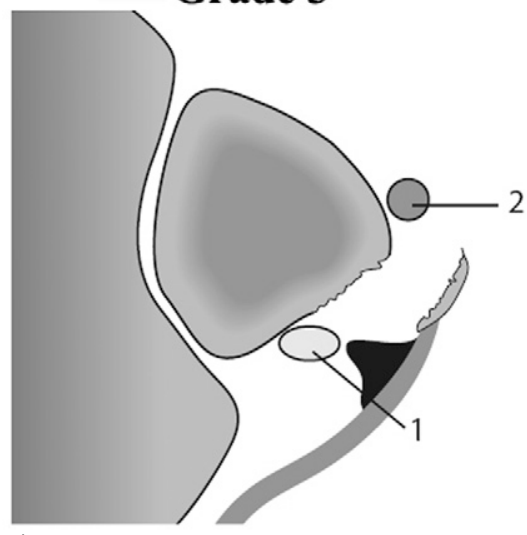

Fig. 2

Graphic replication of the Oden modification ${ }^{7}$ of the Eckert and Davis classification of true peroneal subluxation ${ }^{2}$ (grades 1 through 4 ) (see text). 1 = peroneus brevis tendon, and 2 = peroneus longus tendon. prior magnetic resonance imaging evaluations of the ankles. Three of these patients demonstrated a "possible split tear" of the peroneus brevis tendon (one tear was missed on the magnetic resonance imaging scan, but it was found on ultrasound examination and confirmed intraoperatively), with no other abnormal sheath or tendon findings noted in any of these static studies. No patient had undergone a computerized tomographic scan to quantify the morphology of the retrofibular groove. The average time from the injury to the diagnosis of intrasheath subluxation and treatment was fourteen months (range, two to sixty-five months).

Clinically, all patients had reproducible snapping or clicking of the peroneal tendon with ankle circumduction. This was particularly evident when the ankle was in forceful active eversion and dorsiflexion, and it was reproducibly painful in all ankles-matching the patient's functionally induced pain. All fourteen patients underwent a dynamic axial and longitudinal ultrasound scan of the ankle by a musculoskeletal radiologist (L.N.N.), utilizing a high-frequency linear array transducer ${ }^{8,9}$, which demonstrated intrasheath subluxation (a reversal of the positions of the peroneus brevis and longus tendons) of the peroneal tendons in all patients.

All fourteen patients subsequently underwent a peroneal groove-deepening procedure with reefing of the superior peroneal retinaculum, as described by Zoellner and Clancy ${ }^{4}$, and débridement or repair of any peroneal tendon tears by the senior one of us (S.M.R.). Preoperatively, the scores on the AOFAS ankle-hindfoot scale (with a possible maximum score of 100 points $)^{10}$ and on the visual analog scale pain scale were obtained for all patients. A $10-\mathrm{cm}$ horizontal visual analog scale, ranging from 0 (no pain) to 10 (the worst pain imaginable), was used to assess pain. Despite the linear representation of this assessment tool, pain is not a linear phenomenon and depends, in part, on the individual's prior experience of pain, making his or her reported pain level somewhat difficult to interpret. The same visual scale was used for both preoperative and final follow-up postoperative assessment.

Follow-up evaluation was performed at a minimum of two years (average, thirty-two months; range, twenty-six to fortyfive months) after surgery. At that time, the patients underwent 
The Journal of Bone \& Joint Surgery $\cdot$ JbJs.org

VOlume 90-A · Number 5 - MAY 2008
Intrasheath Subluxation of the Peroneal Tendons

agement. The patients were placed in a lateral position on a well-padded beanbag. A curvilinear incision was made over the path of the peroneal tendons immediately posterior to the fibula centered at the level of the peroneal groove. The incision was in the interneural plane between the sural nerve posteriorly and the superficial peroneal nerve anteriorly. Dissection was continued down to the superior peroneal retinaculum. The retinaculum was sharply dissected at the posterior aspect of the fibula, leaving a 1-mm sleeve of retinaculum still attached to the fibula. The peroneal tendons were then examined, and a tenosynovectomy was performed as needed. Tears in the peroneal tendons were addressed by débridement and suture repair with a 2-0 nonabsorbable suture.

The fibro-osseous retrofibular sheath was osteotomized off the posterior aspect of the fibula as an intact structure and hinged posteriorly, leaving the posterior periosteum intact. A burr was then used to deepen the underlying fibula by removing 7 to $9 \mathrm{~mm}$ of underlying cancellous bone. The fibroosseous sheath was then impacted back into the deepened groove into which the peroneal tendons were replaced. The superior peroneal retinaculum was then reattached to the undersurface of the deepened anterior lip of the peroneal groove through drill-holes in a reefed configuration so as to hold the peroneal tendons firmly contained within the groove. The previously maintained sleeve of retinaculum was then sutured over the top of the repair, augmenting the retinacular reattachment. The peroneal tendons were able to regain their normal mechanics within the sheath.

Postoperatively, the patients were managed with nonweight-bearing for six weeks, but sagittal plane motion of the ankle allowing in-plane motion of the peroneal tendons was started after two weeks. At the six-week point, patients were allowed to bear weight as tolerated in a brace (preventing

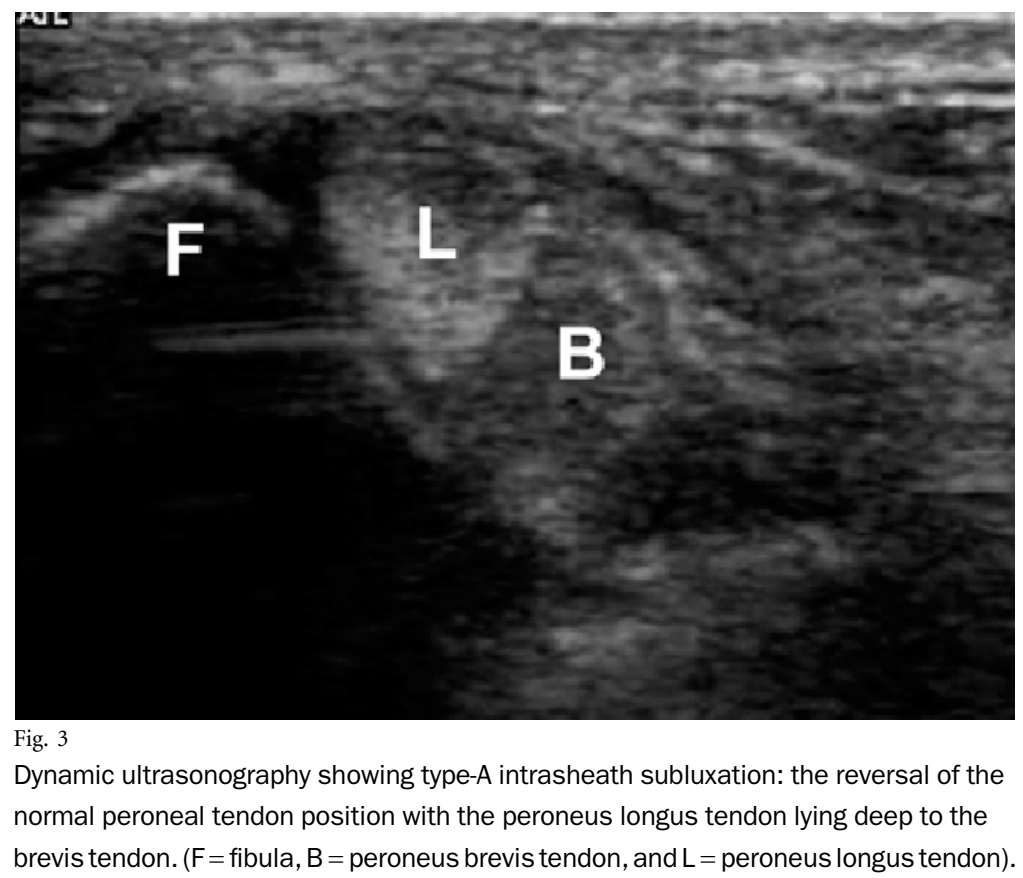




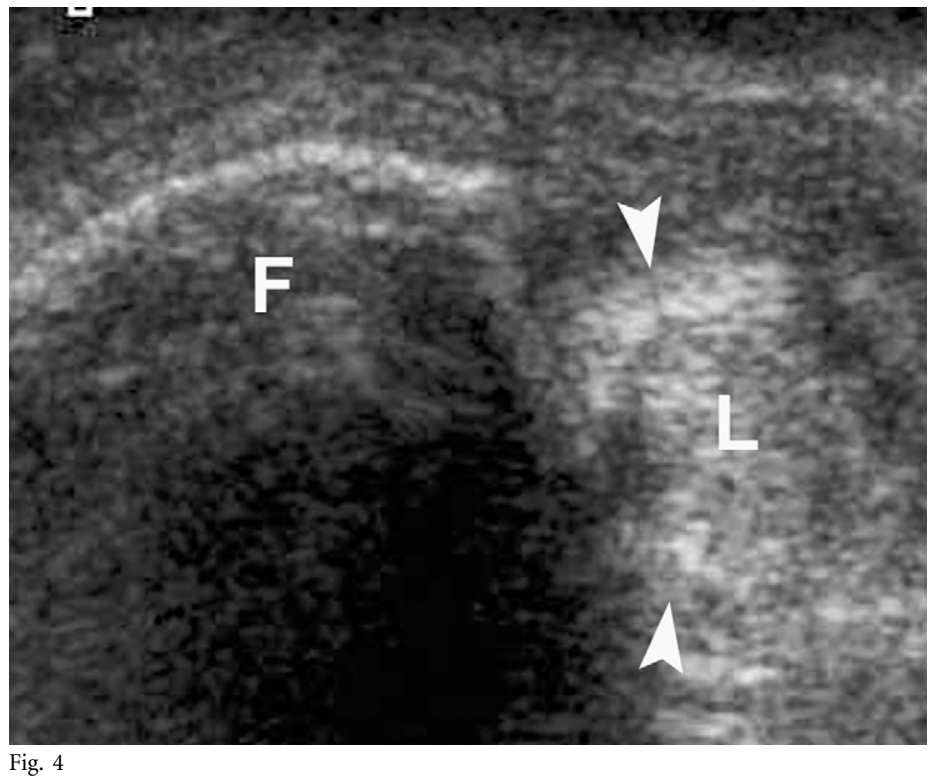

Dynamic ultrasonography showing type-B intrasheath subluxation. The peroneus longus tendon has subluxated through the split peroneus brevis tendon. The white arrowheads point to the two split portions of the peroneus brevis tendon. $\mathrm{F}=$ fibula, and $\mathrm{L}=$ peroneus longus tendon.

eversion and external rotation of the ankle), and physical therapy for peroneal strengthening and proprioceptive training (without the brace) was started.

\section{Statistical Method}

Statistical analysis was undertaken with use of a paired Student $t$ test, with the level of significance set at $p<0.05$. The study was completed with appropriate institutional review board approval obtained through Thomas Jefferson University Hospital. All subjects in the study provided written consent for the surgery.

\section{Results}

\section{Preoperative and Intraoperative Evaluation}

n preoperative ultrasound evaluation, ten patients were found to subluxate the peroneus longus tendon around an intact brevis tendon (Fig. 3) within the intact peroneal sheath while it remained within the peroneal groove (which we called type-A intrasheath subluxation), while four patients were found to have type-B intrasheath subluxation (the peroneus longus subluxating through an associated longitudinal split tear of the peroneus brevis tendon, while remaining within the peroneal groove and sheath) (Fig. 4). The preoperative AOFAS ankle-hindfoot score, determined at the time of the initial evaluation, averaged 61 points (range, 36 to 80 points), while the preoperative visual analog scale pain score averaged 6.8 points (range, 3 to 10 points).

Intraoperatively, the findings of the ultrasound examination were confirmed in all patients. No patient was found to have an avulsion of the superior peroneal retinaculum from the posterior aspect of the fibula, but nine patients had visible distension of the superior peroneal retinaculum. This usually taut band, which holds the peroneal tendons within the peroneal groove, had the appearance of being intact, but it stretched and typically bulged over the underlying tendons. When the retinaculum was opened, a large amount of hypertrophic tenosynovitis was seen around the peroneal tendons, which was adding to the distension of the retinaculum. Five patients had peroneal tendon tears (Fig. 5). Four of these patients had type-B intrasheath subluxation with a longitudinally split tear

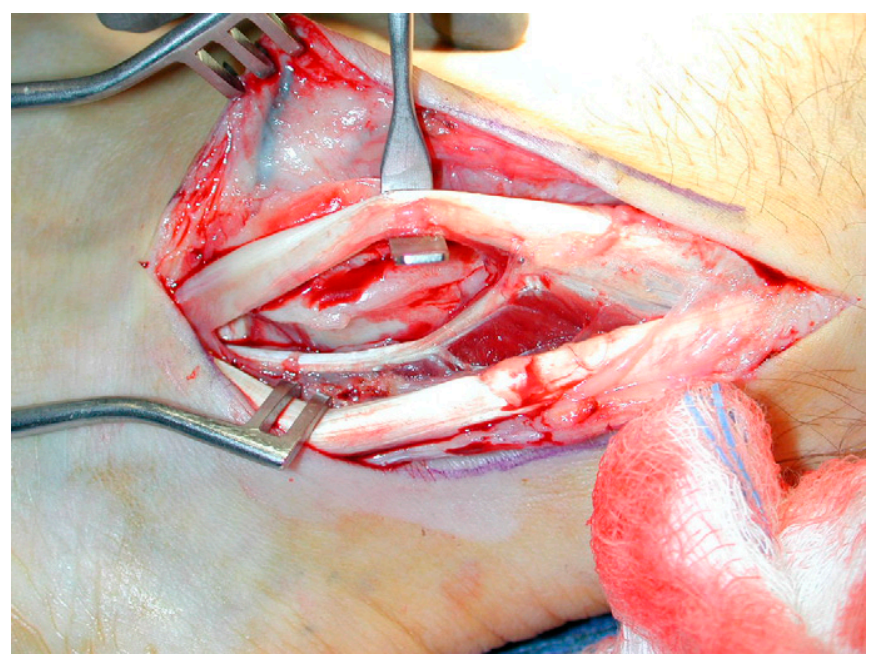

Fig. 5

Surgical demonstration of a longitudinal split within the peroneus brevis tendon through which the longus tendon can subluxate, causing painful snapping. 
in the peroneus brevis tendon. One of these four also had a split tear of the peroneus longus tendon. One patient with type-A intrasheath subluxation also had fraying of the peroneus brevis tendon without the peroneus longus tendon passing through the tear. The peroneal tendon tears were débrided (two patients), if $<40 \%$ of the tendon was involved, or were repaired in a tubularized fashion (four patients) with 2-0 braided nonabsorbable running sutures.

Palpation of the peroneal groove on the posterior aspect of the fibula was performed by the surgeon in all patients. In thirteen of the fourteen patients, a convex (ten patients) or very flat groove (three patients) was present. Anecdotally, review of the operative reports for the forty-three patients with true peroneal subluxation treated by the same surgeon who performed the correction in the ankles with intrasheath subluxation (outlined in Table I) demonstrated that twenty-six fibulae $(60 \%)$ had a nonconcave peroneal groove.

\section{Follow-up Evaluation}

Final clinical and dynamic ultrasound evaluation was performed at an average of thirty-two months (range, twenty-six to forty-five months) after surgery. The ultrasound evaluation was performed by the same radiologist who had done the prior preoperative evaluation. Thirteen of the fourteen patients demonstrated no persistent intrasheath subluxation of the peroneal tendons. In one patient (Case 9) with type-B subluxation, recurrent intrasheath subluxation could be reproduced on forceful ankle eversion and dorsiflexion. Interestingly, the preoperatively demonstrated tear of the peroneus brevis tendon was no longer seen. Rather, the peroneus longus tendon was subluxating around an intact brevis tendon (type A). Despite this, the patient still demonstrated a marked improvement in the AOFAS (from 50 to 85 points) and visual analog scale scores (from 4 to 0 ) and rated the result as good at twenty-five months after surgery.

The postoperative AOFAS scores averaged 93 points (range, 80 to 100 points), which was an average of 32 points higher than the preoperative AOFAS score $(\mathrm{p}<0.001)$. The average postoperative visual analog scale pain score was 1.2 (range, 0 to 3 ), which was 5.6 points (82\%) lower than the average preoperative score $(\mathrm{p}<0.001)$.

The patients were asked to assess the result as excellent, good, fair, or poor. While this is not a validated outcome measure, it is used to demonstrate how the individual patients subjectively viewed the results of the procedure. Nine patients rated the result as excellent; four, as good; and one, as fair. No patient rated the result as poor. The one fair result was in a twenty-eight-year-old woman (Case 13) who had a type-A subluxation. Despite a 28-point improvement in the AOFAS score, she complained of persistent weakness of the peroneal musculature and a perception of instability of the ankle despite extensive physical therapy and normal findings on stress radiographs of the ankle. All fourteen patients stated that they would have the same procedure done again or would recommend it to a friend if needed. The results are summarized in a table in the Appendix.

\section{Discussion}

Many patients with symptoms and mechanisms consistent with subluxation or dislocation of the peroneal tendons do not have reproducible clinical signs or objective studies to confirm the diagnosis. Most radiographic studies, such as magnetic resonance imaging or computed tomography scans, are static and do not facilitate the diagnosis of a motility disorder of the tendons. We previously demonstrated the reliability and accuracy of dynamic testing of the peroneal tendons under ultrasound visualization'. On the basis of the dynamic ultrasound technique, we propose a new category of peroneal motility dysfunction, which we have termed intrasheath subluxation of the peroneal tendons (Fig. 6). Two subtypes were encountered. Type A involves the peroneus brevis and longus tendon snapping over one another and switching their relative positions (the longus tendon comes to lie deep and medial to the brevis tendon) within the peroneal groove without a tear in the tendons or disruption of the superior peroneal retinaculum. In the other subtype (type B), the peroneus longus tendon subluxates through a longitudinal split tear within the peroneus brevis tendon with a portion of the longus tendon coming to lie deep to the brevis tendon at this level. Once again, the superior peroneal retinaculum is not disrupted in this subtype. In all of these cases, the peroneal tendons remain within the intact peroneal retinaculum, but the brevis and longus tendons reverse their anatomic locations within the peroneal groove, causing reproducible painful symptoms.

In a prior literature review, three case reports on six patients with similar intrasheath subluxation of the peroneal tendons were found. The diagnoses were made either intraoperatively ${ }^{11,12}$ or clinically ${ }^{13}$. In all patients, the symptoms were recalcitrant to nonoperative management. Five patients were subsequently managed with resection of a part of the peroneus brevis tendon, while the sixth patient underwent surgical transfer of the tendons under the calcaneofibular ligament. All patients had a good outcome.

In this study, we showed that intrasheath subluxation of the peroneal tendon can be corrected with a peroneal groovedeepening and retinacular reefing procedure (combined with tendon repair when a tear is present), with good or excellent clinical results seen in thirteen of our fourteen patients. This technique allows preservation of the peroneal tendons, preventing potential weakness, which may result from resection of the peroneus brevis tendon, a treatment that has been reported in the literature ${ }^{11,13}$.

Although retinacular reefing alone has been reported for peroneal subluxation in other studies ${ }^{14-16}$, it is unlikely to have a high success rate in the treatment of intrasheath subluxation as the superior peroneal retinaculum is intact in most patients. Additionally, the convex nature of the fibular peroneal groove, which we consistently found intraoperatively, makes groovedeepening a definitive way to correct the underlying anatomical anomaly.

In 1919, Kelly proposed performing a bone-block procedure, in which a partial-thickness rotational osteotomy of the distal aspect of the fibula was performed to hold the pero- 

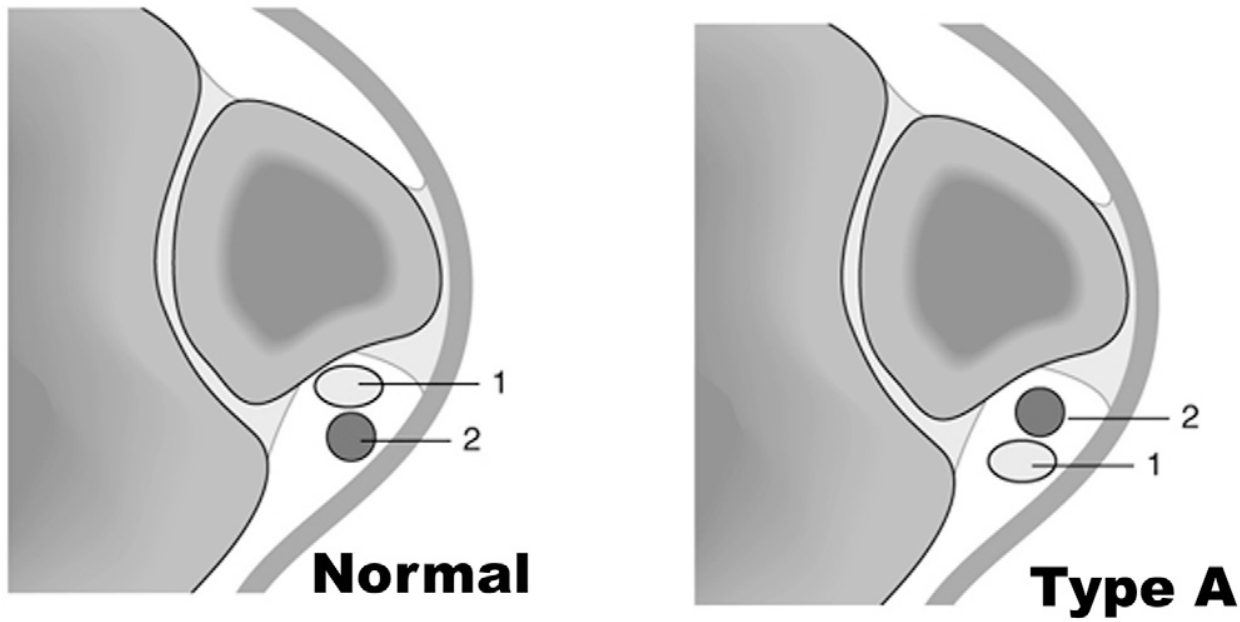

1 - Peroneus Brevis tendon

2 - Peroneus Longus tendon

\section{Classification of Peroneal tendon Intrasheath subluxation}

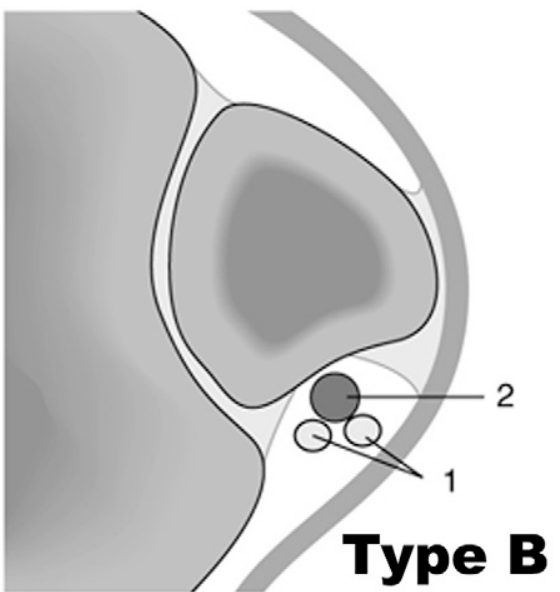

Fig. 6

Classification system for intrasheath subluxation of the peroneal tendons.

neal tendons in position ${ }^{17}$. While early studies showed good results $^{18}$, high rates of nonunion and failure diminished the popularity of this procedure ${ }^{19}$.

The peroneal groove-deepening procedure, wherein bone is resected from beneath the fibrous groove at the distal portion of the fibula, is designed to restore the anatomic concavity of the retrofibular region in which the peroneal tendons run. The superior peroneal retinaculum is then repaired and reattached to the deep portion of the new groove through drill-holes in a reefed configuration. This procedure has been shown to offer good long-term results for peroneal tendon dislocation and/or subluxation $^{4,20-22}$. This procedure additionally reduces the pressure on the peroneal tendons within the groove during function, allowing better return to function ${ }^{23}$. In the current study, the same procedure was used for patients with intrasheath subluxation and demonstrated good or excellent results in thirteen of the fourteen patients.

This study has some limitations. The number of patients is small because of the uncommon nature of this condition. The study was performed as a retrospective review of prospectively collected data obtained at the time of initial evaluation. The final follow-up evaluation was performed prospectively. An additional potential limitation of the study is that patients were assessed with the AOFAS scoring system, which, while in common use, is not a validated outcome measure.

In summary, intrasheath subluxation of the peroneal tendons should be considered a diagnosis in patients with painful retrofibular clicking and dysfunction, without frank subluxation of the tendons out of the peroneal groove. Dynamic ultrasound scanning is a useful and reproducible way to confirm the diagnosis. It is performed while the patient actively dorsiflexes and everts the ankle. Two subtypes of intrasheath subluxation, with and without a tear in the peroneus brevis tendon, can be found. Surgical deepening of the peroneal groove with repair of any tendon tears has been shown in this series to reliably correct this condition.

\section{Appendix}

eA A table showing demographic data and outcome results eA of all patients in this paper is available with the electronic versions of this article, on our web site at jbjs.org (go to the article citation and click on "Supplementary Material") and on 
The Journal of Bone \& Joint Surgery - Jbjs.org VOlume 90-A · Number $5 \cdot$ May 2008
Intrasheath Subluxation of the Peroneal Tendons

925 Chestnut Street, Philadelphia, PA 19107.

E-mail address for S. Raikin:

steven.raikin@rothmaninstitute.com

Levon N. Nazarian, MD

Division of Diagnostic Ultrasound, Department of Radiology,

Thomas Jefferson University Hospital, 132 South 10th Street,

Philadelphia, PA 19107

\section{References}

1. Monteggia GB. Instituzini chirurgiche. Parte secondu. Milan, Italy; 1803. p 336-41.

2. Eckert WR, Davis EA Jr. Acute rupture of the peroneal retinaculum. J Bone Joint Surg Am. 1976;58:670-2.

3. Sarmiento A, Wolf M. Subluxation of peroneal tendons. Case treated by rerouting tendons under calcaneofibular ligament. J Bone Joint Surg Am. 1975;57:115-6.

4. Zoellner G, Clancy W Jr. Recurrent dislocation of the peroneal tendon. J Bone Joint Surg Am. 1979;61:292-4.

5. Arrowsmith SR, Fleming LL, Allman FL. Traumatic dislocations of the peroneal tendons. Am J Sports Med. 1983;11:142-6.

6. Stover CN, Bryan DR. Traumatic dislocation of the peroneal tendons. Am J Surg. 1962;103:180-6.

7. Oden RR. Tendon injuries about the ankle resulting from skiing. Clin Orthop Relat Res. 1987;216:63-9.

8. Magnano GM, Occhi M, Di Stadio M, Toma' P, Derchi LE. High-resolution US of non-traumatic recurrent dislocation of the peroneal tendons: a case report. Pediatr Radiol. 1998;28:476-7.

9. Neustadter J, Raikin SM, Nazarian LN. Dynamic sonographic evaluation of peroneal tendon subluxation. AJR Am J Roentgenol. 2004;183:985-8.

10. Kitaoka HB, Alexander IJ, Adelaar RS, Nunley JA, Myerson MS, Sanders M. Clinical rating systems for the ankle-hindfoot, midfoot, hallux, and lesser toes. Foot Ankle Int. 1994;15:349-53.

11. Harper MC. Subluxation of the peroneal tendons within the peroneal groove: a report of two cases. Foot Ankle Int. 1997;18:369-70.

12. McConkey JP, Favero KJ. Subluxation of the peroneal tendons within the peroneal tendon sheath. A case report. Am J Sports Med. 1987;15:511-3.
13. Stukenborg-Colsman $C$, Wirth $C J$. [Resection of the tendon of the peroneal brevis muscle in "clicking" peroneal tendons-a report of 3 cases]. Z Orthop Ihre Grenzgeb. 2000;138:265-8. German.

14. Adachi N, Fukuhara K, Tanaka H, Nakasa T, Ochi M. Superior retinaculoplasty for recurrent dislocation of peroneal tendons. Foot Ankle Int. 2006;27:1074-8.

15. Ferran NA, Oliva F, Maffulli N. Recurrent subluxation of the peroneal tendons. Sports Med. 2006;36:839-46.

16. Tan V, Lin SS, Okereke E. Superior peroneal retinaculoplasty: a surgical technique for peroneal subluxation. Clin Orthop Relat Res. 2003;410:320-5.

17. Kelly RE. An operation for the chronic dislocation of the peroneal tendons. Br J Surg. 1919;7:502-4.

18. Micheli $\amalg$, Waters $P M$, Sanders DP. Sliding fibular graft repair for chronic dislocation of the peroneal tendons. Am J Sports Med. 1989;17:68-71.

19. Larsen E, Flink-Olsen M, Seerup K. Surgery for recurrent dislocation of the peroneal tendons. Acta Orthop Scand. 1984;55:554-5.

20. Slätis $P$, Santavirta $S$, Sandelin J. Surgical treatment of chronic dislocation of the peroneal tendons. Br J Sports Med. 1988;22:16-8.

21. Porter D, McCarroll J, Knapp E, Torma J. Peroneal tendon subluxation in athletes: fibular groove deepening and retinacular reconstruction. Foot Ankle Int. 2005;26:436-41.

22. Mendicino RW, Orsini RC, Whitman SE, Catanzariti AR. Fibular groove deepening for recurrent peroneal subluxation. J Foot Ankle Surg. 2001;40: 252-63.

23. Title $\mathrm{Cl}$, Jung HG, Parks BG, Schon LC. The peroneal groove deepening procedure: a biomechanical study of pressure reduction. Foot Ankle Int. 2005;26:442-8. 